\title{
Conflict emerges over value of handwashing
}

Previously published at www.cmaj.ca

$\mathrm{T}$ here's no evidence that good hand hygiene practices prevent influenza transmission, according to a Council of Canadian Academies report commissioned by the Public Health Agency of Canada (PHAC).

But N95 particulate respirator-type masks are a proven "final layer of protection" against even the smallest viral particles of influenza, according to Influenza Transmission and the Role of Personal Protective Respiratory Equipment: An Assessment of the Evidence, a report prepared by an expert panel on influenza and personal protective respiratory equipment chaired by Dr. Donald Low, microbiologist-inchief at Mount Sinai Hospital in Toronto, Ontario (www.science advice.ca/ documents/(2007-12-19) _Influenza_PPRE_Final_Report.pdf).

Despite those 2007 findings, PHAC still recommends handwashing as the primary preventive measure against flu transmission. The agency also states on its website that there is no evidence that wearing masks "will prevent the spread of infection in the general population. Improper use of masks may in fact increase the risk of infection."

Moreover, PHAC states in an email to CMAJ that "there is substantial evidence to support hand hygiene as a basic premise of infection prevention and control measures." The agency also indicated that its hand hygiene recommendations are based on a combination of expert opinion and evidence, including a recent Cochrane Collaboration systematic review (BMJ 2009;339:b3675) .

But the contradictory evidence and recommendations on preventive measures and other pandemic (H1N1) 2009 issues leaves Canadian doctors at a loss as to the best advice to provide patients, says College of Family Physicians of Canada President Dr. Sarah Kredentser.

"The average family physician is confused and that's partly because there is a lot of conflicting evidence, and

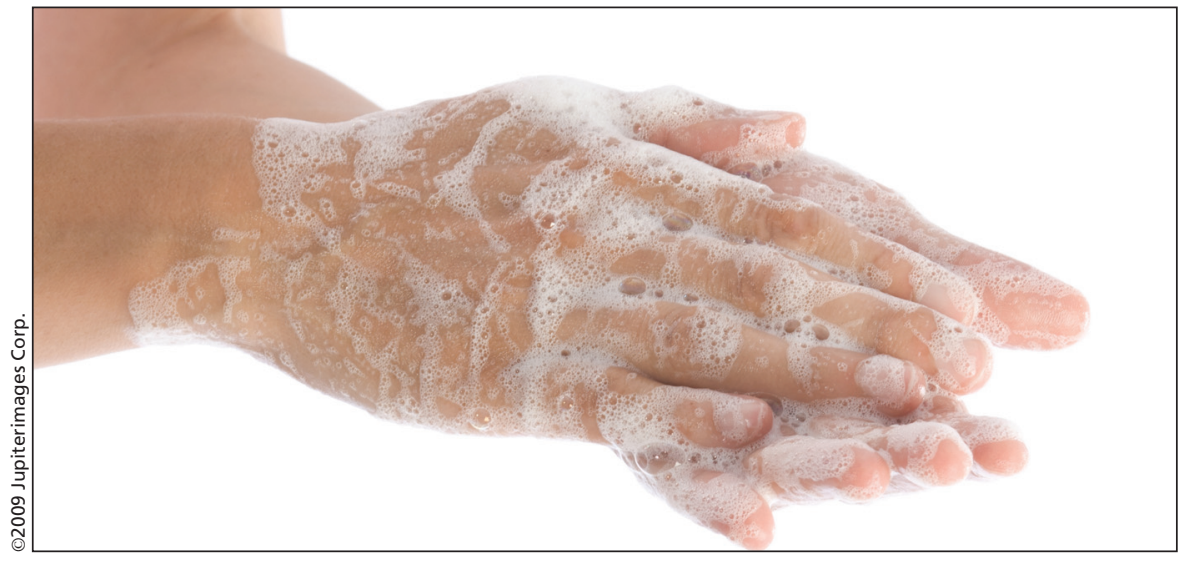

Prominent microbiologist Dr. Donald Low argues that the Public Health Agency of Canada's hand hygiene recommendations "are not evidence-based."

things change day by day," Kredentser says, adding that there's a need for the experts to get the information right and then get it out quickly to family physicians. To that end, the college is now working with PHAC, the Canadian Medical Association and other bodies to craft a one-page influenza guideline for physicians to use in the community.

The absence of any kind of national guidelines or strategies "makes it tough for physicians in practice. In this kind of situation, physicians actually want to be told: What do I do? How do I triage patients? What steps do I take to keep the office open?" Kredentser says, adding that even providing vaccination advice to patients is problematic given the ongoing national controversy over an unpublished study that indicates that getting the seasonal flu vaccine may double the risk of contracting pandemic (H1N1) 2009.

According to the Council of Canadian Academies report, though, there's no conflicting advice regarding handwashing or the use of $\mathrm{N} 95$ respirators.

Low argues that the PHAC's hand hygiene recommendations "are not evidence-based." Noting that research on influenza transmission is limited, he adds that in the absence of adequate evidence, recommendations are often just "expert opinion."

Handwashing is based on practical, rather than scientific, considerations, he says. It is "a simple thing to do and it may protect you from some other illnesses."

But current evidence shows that influenza is transmitted primarily at a short range of 1-2 metres by inhaling particles from an infected person ("inhalation transmission"), although the virus can survive on surfaces and, theoretically, transmission can occur from contaminated surfaces to hands ("contact transmission"), according to the report, which was drafted in 2007 by 13 senior academic and clinical physicians, nurses and a judge. The expert panel, which examined 128 sources of evidence, was struck by the Council of Canadian Academies in response to a request from PHAC. The council was established in 2005 with a $\$ 30$-million founding grant from the government of Canada to provide independent assessments of scientific issues for governments and other bodies.

Low explains that receptors for the virus are located farther back in the respiratory tract than those for rhinoviruses (colds). It is more difficult for viral particles to reach the pharynx, trachea, bronchi and alveoli - where influenza receptors are found - from a contaminated hand touched to the mouth or nose. The particles can more readily reach the sites if they are inhaled. 
"Every time you talk, laugh, cough, sneeze, you're generating particles that are coming out of your mouth that are various sizes," Low says. "Ballistic" particles more than 100 microns in diameter fall to the ground. But smaller particles ranging from 0.1 to 100 microns stay in the air from seconds to days, depending on humidity, airflow and ultraviolet light. These particles can be inhaled deeply into the respiratory tract, with smaller ones capable of reaching the tracheobronchial and alveolar tissues.

In practice, studies show the greatest risk is within one metre, Low adds. "Whether someone is infectious will vary [with] the amount of virus. There's a huge dilutional factor right away as soon as you get away from the person infected."

Surgical masks - designed to protect patients from surgeons - provide some protection against contact and inhalation transmission, but allow air in the sides and do not meet an established standard, Low explains.

N95 masks, however, do meet the test. Created to protect workers in the construction industry from breathing in particulates and widely available in hardware stores, they must meet standards set by the US National Institute for Occupational Safety and Health. They fit tightly on the face and block particles as small as 0.1 micron.

While PHAC states on its website that it does not recommend that healthy people wear masks as they go about their daily lives, Low says N95 masks have a role in protecting the public. "If you had somebody at home with influenza, wearing an N95 mask would be very appropriate."

Canada's Chief Public Health Officer, Dr. David Butler-Jones, states on PHAC's website, though, that it can be easy to get a false sense of security from wearing the mask.

Low counters: "I don't know where the false sense of security would come from." - Carolyn Brown, Ottawa, Ont. and Wayne Kondro, CMAJ

DOI:10.1503/cmaj.109-3066

\section{Shift toward capitation in Ontario}

Previously published at www.cmaj.ca

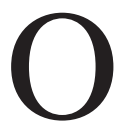
ntario family doctors are shifting from fee-for-service to capitation in ever-increasing numbers. Supporters of capitation systems say this is good news for both doctors and patients, though they warn that such systems can be complicated and difficult to operate effectively.

Canadian capitation experts say there has been little momentum in most provinces toward paying doctors annual fees for each patient - except in Ontario. About a quarter of family physicians in Ontario are paid via capitation, many abandoning fee-for-service only recently. About two-thirds of Ontario patients are enrolled in capitation systems or so-called blended systems, which retain some feefor-service elements.

The Ontario government first dabbled in capitation in the 1970s through its Health Services Organization program. In 2002, physicians were allowed to adopt the Family Health Network model, also based on global payment. But it wasn't until the 2005 introduction of the Family Health Organization program - which covers more services and offers a higher capitation rate that Ontario doctors began switching in large numbers. This model became so popular, in fact, that the government at one point issued a temporary moratorium to slow down the massive wave of doctors making the transition.

"In 2002, doctors in Ontario were very skeptical. ... There was a lot of suspicion of government at the time, but then they realized that their incomes would go up and their workloads would maybe stabilize or go down. Of Ontario physicians who went into capitation, virtually none have gone back," says Dr. Richard Glazier, senior scientist with the Institute for Clinical Evaluative Sciences in Toronto, Ontario.

The Ontario government has put much effort into promoting capitation because expenses are very predictable in this payment model and because it allows for the creation of family health teams. Under a fee-for-service system, family physicians have little financial incentive to work as part of a team of health care providers. Sometimes, fee-for-service doctors perform duties they may be overqualified for - giving allergy shots, for example - because they would not be reimbursed if the task was performed by nurses. Such teams are seen as a way to maximize the effectiveness of family doctors, a scarce resource in Ontario.

"The family health team is a flagship initiative of this government," says Dr. Brian Hutchison, editor-in-chief of Healthcare Policy.
These teams not only relieve physicians of performing easier tasks, but also allow them to relay patients to health care professionals who are more qualified to offer certain services. A team could, for instance, include a pharmacist to assist patients with their medications and a psychiatrist to help them with mental health issues. Such a team could allow a practice to enrol more patients, and thus collect more capitation fees.

"From the patient's perspective, you go to one place and more of your needs are better met," says Dr. William Hogg, director of the C.T. Lamont Primary Health Care Research Centre in Ottawa, Ontario.

Proponents of capitation say it encourages high-quality care rather than maximizing throughput. In a feefor-service system, according to Hogg, there is a "perverse incentive" to bring patients back more than once for problems that could be addressed in one visit. On the other hand, fee-for-service does encourage doctors to work hard and see many patients.

To encourage doctors who switch to capitation systems to still see as many patients as before, the Ontario government pays them bonuses for meeting certain targets. These include getting a set percentage of their female patients in a certain age range to have mammograms 